\title{
Trabalho e saúde sob a ótica de domésticas e pedreiros do município da Serra, ES
}

\author{
Roberta Melo Vello Poldi, Luiz Henrique Borges e Maristela Dalbello-Araujo \\ Programa de Pós-Graduação em Saúde Coletiva da \\ Universidade Federal do Espírito Santo (Vitória, ES)
}

\begin{abstract}
Este artigo tem como objetivo identificar e analisar as relações entre trabalho e processo saúde-doença sob a ótica de trabalhadoras domésticas e trabalhadores da construção civil, adscritos a uma unidade de saúde da família do município da Serra, ES. Faz parte de pesquisa exploratória de abordagem qualitativa que utilizou Grupos Focais como técnica de coleta de dados e Análise do Discurso temática para tratamento dos dados. Para esses trabalhadores o trabalho é antes de tudo uma necessidade para a sobrevivência, interferindo sobremaneira no tempo de estudo e lazer. Dessa forma, tornam-se reféns dessas ocupações e se veem impedidos de ascender socioeconomicamente. Foram encontradas também expressões das relações sociais de gênero, em que as mulheres são sobrecarregadas pela dupla jornada de trabalho. Possuem uma visão ampliada de saúde articulando-a com as condições materiais de existência. Esta pesquisa dá visibilidade ao trabalho como um dos fatores determinantes do processo saúde-doença e aponta a necessidade de o sistema de saúde brasileiro incluir esse aspecto em sua formulação.
\end{abstract}

Palavras-chave: Saúde do trabalhador, Concepção de saúde, Trabalhadores.

Perceptions of bricklayers and maids on health and work at Serra, ES

This paper aims to analyze the connections between labor and the health-disease process as experienced by maids and construction workers from a Family Health Unit based in Serra, ES. It is part of an exploratory, qualitative research that used focal group methodology for data collection, and thematic categories were emphasized through content analysis for data review. The studied groups of workers view labor as a basic need for survival, greatly affecting the study and leisure time; therefore, they become captives of these occupations and it [ultimately] determines their powerlessness for socioeconomic ascension. Expressions of social relations of gender, where women are burdened by the double workday were also described. These workers have a broader, pluralistic and holistic concept of health as they articulate it with material conditions of existence. This study reappraises the role of labor as one of the determinant factors of the health-disease process and also highlights the need for the Brazilian Health System to include this topic on its formulations.

Keywords: Occupational health, Health concepts, Workers.

\section{Introdução}

$\mathrm{O}$ Sistema Único de Saúde (SUS) ainda não incorporou de forma efetiva em suas ações a concepção de que o trabalho ocupa lugar central na vida dos indivíduos e suas relações com o espaço socioambiental, ou seja, o importante papel que o trabalho exerce na determinação do processo saúde-doença, não apenas dos trabalhadores diretamente envolvidos nas atividades produtivas, mas também da população em geral (Hoefel, Dias \& Silva, 2005).

O processo de reestruturação produtiva que altera a configuração do trabalho tem causado fortes consequências para os trabalhadores, como o desemprego estrutural, a precarização do trabalho e o crescimento do setor informal, com perda de direitos trabalhistas e previdenciários, historicamente conquistados. $\mathrm{O}$ desemprego estrutural repercute na organização dos sindicatos, obrigando-os a deslocar o foco de atuação na preservação de postos de trabalho, deixando em segundo plano a luta pela melhoria das condições em que o trabalho é executado (Alves, 2000; Dias, 2007).

Ao lado disso, toma corpo um movimento de feminilização do mercado de trabalho, caracterizado por um aumento da participação proporcional das mulheres, embora com uma 
clara desvantagem em relação aos indivíduos do sexo oposto, tanto do ponto de vista do rendimento quanto da perspectiva da qualidade das ocupações criadas e da sobrecarga decorrente do acúmulo com as atividades domésticas e familiares (Souza, 2001; Hirata \& Kergoat, 2007; Kergoat, 2010).

Essas mudanças impactam o trabalho, o modo de vida e as condições de saúde da população e fazem com que o SUS tenha que assumir um papel diferenciado, ao se colocar como a única política pública de cobertura universal para o cuidado da saúde dos trabalhadores (Dias \& Hoefel, 2005), uma vez que possui uma rede de serviços de saúde presente em todas as regiões do País e, pode-se dizer, em praticamente todos os municípios brasileiros, com o potencial de atender a todos, independentemente de sua inserção no mercado de trabalho (Santos, 2001).

Diante disso, foi realizada pesquisa ${ }^{1}$, objetivando identificar e analisar as necessidades de saúde sob a ótica de moradores, com diferentes inserções ocupacionais, adscritos a uma unidade de saúde da família do município da Serra-ES. Mais especificamente, buscou-se analisar como a condição de trabalhador se expressa nas concepções desses moradores sobre o processo saúde-doença e que especificidade traz na utilização dos serviços de saúde, principalmente da unidade básica de saúde.

A pesquisa foi realizada em Jardim Carapina, um bairro criado a partir de invasões nos anos 1980 que, em 2000, contava com aproximadamente 10.225 habitantes (IBGE - Instituto Brasileiro de Geografia e Estatística, 2000). Segundo informações do líder comunitário, hoje o número chegaria a 18 mil. Em 2000, 71,14\% dos moradores possuíam renda inferior a dois salários mínimos e quase 20\% não tinham rendimento mensal (IBGE, 2000). O bairro se caracteriza pela presença de comércio, uma creche e três escolas de nível fundamental; muitas igrejas (Católica, Maranata, Batista, Assembleia de Deus, entre outras); não há praças públicas, quadras ou jardins. Segundo Poldi (2007), havia no bairro 2.473 famílias cadastradas no SUS, das quais somente 5,5\% possuíam plano de saúde. Quase todas as famílias têm abastecimento de água e coleta de lixo; entretanto, mais da metade (51,3\%) não possui sistema de esgoto, sendo os dejetos destinados em fossa ou a céu aberto. Os sujeitos da pesquisa são representantes das ocupações mais frequentes no bairro: construção civil e as trabalhadoras domésticas (Poldi, 2007).

Este artigo analisa parte dos resultados obtidos na pesquisa, mais especificamente a expressão e as concepções dos participantes acerca do processo saúde-doença e das relações entre trabalho, saúde e condições de vida.

\section{Percurso metodológico 2}

Trata-se de pesquisa exploratória de abordagem qualitativa, realizada de março a maio de 2008. Apesar das inúmeras dificuldades operacionais para a execução desse tipo de campo, valorizamos a discussão em grupo como estratégia da abordagem qualitativa e optamos por utilizar o Grupo Focal (GF) como técnica de coleta dos dados (Hassen, 2002; Minayo, 2007).

Uma das maiores dificuldades constituiu-se na montagem dos grupos. Para sua viabilização utilizamos os préstimos de informantes-chave, moradores do bairro, engajados nos movimentos sociais da comunidade, das pastorais operária e da criança. Essa contribuição foi

1 Este artigo trata de parte dos objetivos analisados na dissertação de mestrado defendida por Poldi (2008), Relação entre trabalho e necessidades de saúde sob a ótica de moradores adscritos a uma unidade de Saúde da Família no município da Serra, ES.

2 A coleta dos dados foi iniciada apenas após ter sido autorizada previamente pela Secretária Municipal de Saúde da Serra, pela diretora do Departamento de Assistência Ambulatorial (DAAM), pela coordenadora da Unidade de Saúde da Família de Jardim Carapina e pelo Comitê de Ética em Pesquisa da UFES. 
fundamental no recrutamento dos participantes e na solução de problemas operacionais, como local e segurança para a realização dos grupos. Realizamos três encontros numa sala da Igreja Batista, local seguro e não identificado com os serviços de saúde, contribuindo para a expressão de ideias dos moradores.

O primeiro grupo contou com a participação de 13 mulheres e o segundo com a de 15 homens. Foram conduzidos pela pesquisadora como moderadora, com o auxílio de um relator, que utilizou três gravadores de som e uma filmadora. As discussões duraram aproximadamente uma hora e trinta minutos cada. Os resultados indicaram especialmente as diferenças de gênero e sua relação com o trabalho, motivo pelo qual se optou pela realização de um terceiro grupo misto, com quatro homens e três mulheres.

A análise dos dados foi feita por meio da análise temática, que consiste em destacar núcleos de sentido que compõem uma comunicação, pois a presença de determinados temas denota valores de referência e os modelos de comportamento presentes no discurso (Minayo, 2007). Destacaram-se como eixos norteadores: o significado do trabalho para a vida; a interferência do trabalho no dia a dia; a necessidade de boas condições de trabalho para a saúde; os riscos percebidos e morbidades referidas.

\section{Significado do trabalho para a vida}

As falas recorrentes nas discussões de grupo ressaltam a relevância das transformações no mundo do trabalho e suas consequências sobre as demais esferas da vida social, entre as quais a família, polo de reprodução intimamente articulado com o polo da produção. Como afirma Borges (2006), nesse início de século o trabalho e a família continuam sendo os eixos organizadores da vida de homens e mulheres. Para Goldani (2002), o mito da separação entre o mundo do trabalho e o mundo da família acabou, e hoje há um reconhecimento da importância das relações entre eles. Ressaltamos que as mudanças que se operam nas relações de trabalho vão além da contradição emprego-desemprego: o trabalho assalariado vem perdendo a sua centralidade como estrutura, porém em seu sentido ontológico continua sendo elemento central na vida do sujeito histórico, uma categoria de interpretação da condição humana (Torres, 2002, citado por Coutinho \& Gomes, 2006).

O trabalho remunerado, extradomiciliar, para grande parte das trabalhadoras domésticas desses grupos, é apontado como uma necessidade para a sobrevivência.

Só sou eu e Deus. Eu não tenho marido para me ajudar, se eu não trabalhar eu passo necessidade. Se eu não trabalhar, quem vai colocar comida dentro de casa para mim comer (R11).

Segundo o IBGE (2000), no Brasil, 30\% das unidades domésticas urbanas são lideradas por mulheres. É comum, entre famílias pobres, a mulher ser a chefe da casa e da família, arcando sozinha com todas as despesas. A necessidade de participação no orçamento doméstico é apontada como a principal razão para se trabalhar entre mulheres que vivem conjugalmente, pois o cônjuge não tem conseguido sozinho prover todas as necessidades familiares ou está desempregado. Rodrigues (1978), ao estudar a realidade dos operários e operárias da Grande São Paulo, nos anos 1970, já afirmava que o fato de as mulheres trabalharem se deve, muitas vezes, à incapacidade do homem para suprir sozinho as necessidades de recursos materiais da família.

As novas configurações da força de trabalho que acompanham a globalização econômica e a reestruturação produtiva colocam em cena o trabalho precarizado (economia 
informal nos países subdesenvolvidos, perda de direitos trabalhistas e previdenciários, salários mais baixos, etc.) como condição para a continuidade da acumulação capitalista (Alves, 2000). Entretanto, apesar da sua expansão no mercado de trabalho em geral, a precarização tem ocorrido em maior proporção entre as mulheres (Hirata, 2002; Hirata \& Kergoat, 2007; Hirata, 2009; Kergoat, 2010).

Porém, há outra perspectiva do significado do trabalho para as mulheres pesquisadas, que é a satisfação por ter um trabalho, para além daquele exclusivamente de reprodução social, como dona de casa. Sobressai o valor de poder sair de casa e conhecer pessoas diferentes. Parece que ter o próprio dinheiro contribui para que essa mulher não fique totalmente submissa aos desejos do marido.

O trabalho é tudo para mim. Se eu quero uma coisa, vou lá e compro. Se eu quero sair eu não tenho que pedir dinheiro... Quando eu estou de férias, eu arrumo outro bico para fazer porque eu não gosto de ficar em casa. Eu acostumei sair todos os dias, conhecer pessoas diferentes. Meu marido fala que está fazendo um ponto e diz que quando tiver pronto eu não vou mais trabalhar fora. Mas minha vontade não é essa. Pois lá eu não vou ter a mesma independência do que na rua (R13).

Em relação às ocupações de doméstica e diarista, algumas trabalhadoras apontam o preconceito social em relação a essas ocupações, o que, por vezes, as faz esconder essa condição.

Tem certas vezes que você vai fazer um cartão na loja, eu tenho que mentir, senão eles me dão um limite pequenininho (R12).

Uma moradora relatou, inclusive, sentir menos vergonha em assumir exclusivamente o seu papel na reprodução social do que falar que é trabalhadora doméstica, principalmente diante de mulheres escolarizadas. Parece que, entre essas mulheres, poder dedicar-se exclusivamente ao lar e ao cuidado dos filhos é socialmente mais valorizado do que trabalhar fora de casa como trabalhadora doméstica.

É a coisa mais triste você falar "eu sou doméstica". Eu sinto até vergonha. Eu já tive caso de eu falar e ficarem rindo de mim. Uma vez eu fui com o meu marido em um culto. A gente dele vinha me perguntar: "Você está estudando?". "Não, não tô mais." Só falta me perguntar em que série eu parei. "Não trabalho não, eu tomo conta dos meus filhos." Porque onde a gente tava tinha uma que era professora, outra advogada, outra não sei o que. A gente fica meio tensa em falar que é doméstica (R2).

Por outro lado, outras dizem sentir orgulho do que fazem, por ser um trabalho honesto e que sempre as ajudou no sustento próprio e de sua família.

Mas não vai falar que você tem vergonha de ser doméstica. Isso não! Você vai estudar porque quer uma coisa melhor mais tarde, porque doméstica é puxado. Mas vergonha de ser o que você é, aí eu já não concordo. Se me perguntarem eu digo "sou doméstica, cozinheira"! (R6).

Podem-se observar também expressões como "é muita exploração" e "exploram e pagam pouco". A desvalorização dessa ocupação no mercado de trabalho se concretiza na dificuldade de reconhecimento dos direitos trabalhistas, quando uma maior remuneração é negociada em troca da não regulamentação e da manutenção do vínculo informal.

Eu comecei com 15, como doméstica, depois fichei numa firma na XLP, fiquei três anos como cozinheira, saí e hoje eu trabalho como diarista, porque, para você fichar, hoje eles não querem pagar o que você tem na carteira. Se eles te pagam 600, querem te fichar como 390. Fui obrigada a trabalhar em uma casa de família depois de ter uma profissão na carteira, por causa do salário. 
Hoje eu tô trabalhando como diarista, a gente é obrigada a aceitar para ganhar mais dinheiro [...] (V6).

Orupo composto por homens e mulheres destaca também o problema da desvalorização da mão de obra feminina, quando comparada à masculina. Considera essa diferença uma discriminação quando ambos executam a mesma função.

[...] A mesma coisa que o homem faz a mulher faz e ganha menos. O cozinheiro ganha os 600 paus, por que que a mulher tem que ganhar menos? Eu acho muito errado. Não pode acontecer isso. A gente é discriminada (V6).

O trabalho profissional doméstico, precarizado, é uma realidade nas famílias de classes médias e altas brasileiras, com enraizamento cultural. Kergoat (2010) discute o surgimento de um novo paradigma na forma de trabalho profissional em atividades de cuidado nos países ocidentais, decorrente do crescente envolvimento das mulheres na carreira profissional e nos fluxos migratórios de regiões menos desenvolvidas para as mais desenvolvidas. Considera a extensão das relações de classe no entrecruzamento com relações de gênero e raça/etnia, com oposição entre uma nova classe servil (a nova classe operária não industrial, precarizada e com baixos salários) e as novas mulheres empregadoras (que veem seus capitais econômico, social e cultural aumentarem). Com isso, observa-se uma racialização do trabalho profissional em atividades de cuidado, através da naturalização das qualidades que seriam próprias a essa ou àquela etnia, em atividades integradas às famílias, como as de babás, empregadas domésticas e cuidadoras de membros idosos da família.

Assim como para as mulheres, para os homens o trabalho é uma necessidade para sobrevivência de si e de sua família. Alegam que o trabalho na construção civil é muito importante por permitir que pessoas de baixa escolaridade e que vieram do interior possam se inserir rapidamente no mercado de trabalho, já que não depende de qualificação profissional. Por ocasião da realização da pesquisa (em 2008), o mercado da construção civil no Estado do Espírito Santo estava muito aquecido, favorecendo a oferta de serviços e melhores rendimentos.

Para mim, hoje, a construção civil é tudo. É uma forma de eu sobreviver, ganhar um dinheiro... cuidar da minha família. Lá em casa, só quem trabalha sou eu... Então eu tenho que dar graças a Deus que eu ainda tenho conhecimento para que eu possa trabalhar e tô sobrevivendo disso. Eu acho que hoje eu não tenho outra saída a não ser encarar de frente e fazer meu trabalho com amor... Seja a profissão que for, seja um catador de lixo, mas se ele estiver sobrevivendo e está dando certo tem que fazer com amor e carinho (A10).

A maioria, quase todos nós aqui, vinha do interior ou vinha de outra cidade, então o que acontece é que a maioria dessas pessoas aqui tem uma escolaridade baixa, inclusive eu. Então a gente chega aqui, em uma outra cidade e qual a primeira opção que a gente tem? Trabalhar na construção civil. Então, às vezes, não é porque a pessoa gosta da construção civil, é porque ele é empurrado, pois é uma coisa que ele consegue fácil e não depende de escolaridade (A12).

Nesse sentido, as trabalhadoras domésticas e os trabalhadores da construção civil se assemelham, pois essas ocupações representam uma possibilidade para as pessoas de menor nível socioeconômico e escolaridade, que necessitam trabalhar precocemente, se inserirem no mercado de trabalho. Como disse Valla (2002), um trabalho frustrante para as classes populares não significa uma "má escolha”, mas quase sempre uma "única escolha” por causa das poucas ofertas do mercado.

Assim como as domésticas, os pedreiros pensam que seu trabalho é pouco valorizado. Os que trabalham com carteira assinada ganham muito pouco e os que trabalham como autônomos, apesar da possibilidade de melhores rendimentos, não têm direitos trabalhistas ou segurança e sentem-se totalmente desamparados pelo Estado. 
[...] se você trabalha com carteira assinada, você ganha é muito pouco, trabalham mais por falta de opção. A maioria das pessoas que trabalham como pedreiro não tem carteira assinada, não tem INPS [sic], são pessoas que estão desamparadas. O trabalhador autônomo, se sofrer um acidente, se ele precisar de um tratamento para qualquer coisa, está enrolado. Eu não considero uma boa coisa, tanto quem é empregado como quem é autônomo, pois você não é valorizado (A12).

Entretanto, os trabalhadores da construção civil, aqui estudados, ressaltam que sua profissão exige inteligência e criatividade, comparando-a ao ofício de um artista. Por atuarem em uma área em constante evolução tecnológica, estão sempre tendo que lidar com novos produtos, aprendendo na prática, sem nenhum treinamento específico. Reconhecem que um trabalhador instruído tem mais facilidade diante dessas mudanças e incentivam os mais jovens a estudar. Porém, poucos conseguem, pela dificuldade decorrente da necessidade de trabalhar o dia inteiro em um ofício em que é intenso o desgaste físico.

O mercado hoje na construção civil é muito evoluído, por causa do engenheiro, arquiteto e decoradores. É uma área que você nunca sabe tudo, pois tem sempre coisas novas. O pedreiro acaba se tornando um artista, porque ele não está na escola estudando, mas dentro da profissão dele tem que se virar. O pedreiro tem que estar aprendendo todo dia, porque se ele não fizer, se ele não tiver uma mão de obra qualificada, ele fica enrolado para conseguir trabalhar. Hoje esses meninos novos, que trabalham comigo aí, já têm um estudozinho. Mas quando eu pegava essas pessoas mais novas, que não tinha estudo nenhum, que não sabia nem escrever o nome, eu mesmo incentivava [estudar]. Isso é importante sim, mas às vezes o serviço é muito puxado sim e quando chega à noite dica difícil encarar o colégio (A10).

Outro aspecto referido é que, além de valor de produção, o trabalho tem um valor moral e social. A partir disso formulam expressões como "o trabalho engrandece o homem" e "o trabalho dignifica". Entendem que o trabalho como obrigação, por si só, não é bom, mas o respeito, a dignidade, a credibilidade e a própria saúde que ele pode gerar constituem o lado bom do trabalho. Nessa ótica, quem não trabalha tem dificuldade de se inserir socialmente.

Em relação ao trabalho, não é bom, não; ele engrandece a gente, mas que é bom. Mas sem trabalho você é um homem sem confiança, sem moral, sem crédito, pois fica uns cinco anos sem trabalho e chega no comércio e tenta comprar fiado para ver se o cara te vende, que nada. Tudo isso, e tem saúde também, se o cara parar de trabalhar, adoece (V1).

O trabalho ajuda no caráter, na formação da pessoa, a valorizar o que você tem, porque o cara que tem tudo na mão dificilmente dá valor àquilo que ele tem (V3).

\section{Interferência do trabalho no dia a dia}

Entre as mulheres, principalmente entre as que têm filhos pequenos, foi comum a queixa em relação à dupla jornada de trabalho e à falta de apoio dos companheiros nos serviços domésticos. Como, além do trabalho extradomiciliar, continuam com a obrigação do trabalho de casa, e o tipo de atividade realizada nos dois lugares é comum (trabalho doméstico), sentem que um é a extensão do outro. Além disso, é um trabalho cotidiano e inesgotável, o que faz com que considerem mais vantajoso ser homem. Evidentemente, para a mulher que duplica suas tarefas, realizando o doméstico e o extradoméstico, esse aspecto do trabalho ocupando todo o tempo é ainda mais dramático. Antes de qualquer coisa, essa mulher é muito necessária dentro de casa e não tem com quem deixar os filhos. Para trabalhar ela tem que duplicar sua tarefa, cumprindo suas funções dentro e fora de casa (Rodrigues, 1978). Pela ideologia do 
patriarcado, o trabalho doméstico é instituído como tarefa natural da mulher e torna-se, por isso, um obstáculo à liberdade das mulheres no mundo público, à igualdade, à democracia nas famílias e à justiça no mercado de trabalho. Desse modo, por terem sob sua responsabilidade os filhos e as tarefas domésticas, a contabilidade capitalista coloca na conta das mulheres os custos com a reprodução, tornando as mulheres "mais caras" para os empregadores. E é justamente por estar colocada sobre as mulheres essa responsabilidade que os homens ficam desobrigados, como grupo social, dessas tarefas, tornando-se, assim, "mais baratos" e tendo mais tempo livre para o trabalho, o lazer, a organização política. A dupla jornada sobre as mulheres é, portanto, central para a exploração do trabalho no capitalismo (Carta Aberta das Mulheres, 2007).

Nos finais de semana, os homens exercem seu ofício de pedreiro na própria casa, ampliando ou reformando a moradia.

O cara que trabalha na construção, ele trabalha direto, ele não tem folga não, tem sempre uma coisa para fazer em casa. Quase todo mundo que trabalha aqui, trabalha o final de semana em casa (A12).

Tem mais de anos que estou construindo [minha casa]. Vocês repararam que a gente nunca termina de fazer o serviço da gente? Nunca termina (A2).

Apesar de terem relatado que o trabalho interfere diretamente no tempo de estudo e lazer, sobretudo com a família, parecem lidar com essa situação de forma diferenciada das mulheres. Os trabalhadores reconhecem a importância de dar atenção aos filhos, entendendo essa atenção como sair para passear e brincar. No entanto, é a necessidade de trabalhar para poder garantir possibilidades melhores de vida aos filhos que prevalece. Naturalizam essa constatação como se não pudesse ser diferente. Alguns, porém, quando conseguem tempo livre, se dividem entre a Igreja, o lazer e a família.

Na verdade é complicado descobrir um tempo para a família. O domingo que folga para mim o companheiro me cobra de eu ir à Igreja, mas eu gosto do meu horário de diversão também. Eu gosto de ir para a minha pescaria também. Aí que chego em casa exausto, tomo um banho, apago e acabou. É esperar segunda-feira para começar tudo de novo. Eu tô falando a realidade da gente. A oportunidade que eu não tive no passado, hoje eu quero dar para os meus filhos, pois eu sei que faz falta. O que você ganha é para instruir os filhos (A1).

Cyrino (2009) considera que a articulação entre trabalho doméstico e assalariado (mais especificamente, a conciliação entre trabalho e vida familiar) é um dos fatores explicativos principais para as inserções desiguais de homens e mulheres no mercado de trabalho. Os sujeitos de sua pesquisa foram homens e mulheres casados, com diferentes ocupações, escolaridade e renda familiar. Apesar de no seu grupo de estudo não estarem representadas trabalhadoras domésticas e predominarem as donas de casa entre as mulheres, suas conclusões possibilitam um diálogo com as expressões das trabalhadoras abordadas neste artigo. Considerando-se os diferentes modos de regulação do tempo sob a ótica de gênero, pôde verificar que o trabalho é central na vida das mulheres, ocupando uma jornada de trabalho (esforços despendidos no domicílio e fora dele) consideravelmente maior do que para os homens. Para a autora, a permanência da responsabilidade maior para as mulheres em relação às atividades no lar (de reprodução da força de trabalho, necessitando de ocupação do tempo principalmente nas atividades que constituem alimentação, asseio e cuidado), a despeito de sua expansão no trabalho assalariado em proporções cada vez maiores, pode ser explicada também pelas relações de poder implicadas nas relações de gênero. Essas relações se manifestam nas representações de mulheres e homens estudadas, nas quais elas reconhecem a atividade no domicílio como uma atividade de trabalho necessária de ser desenvolvida, enquanto eles, quando a fazem, lhe dão o significado de lazer. 
Para as mulheres, a falta de tempo para se dedicar aos filhos é um fator de muita angústia e estresse. Sentem remorso por deixarem os filhos em casa e saírem para trabalhar. Algumas reagem a isso com sentimento de culpa, outras com agressividade, outras procuram contornar a situação e tirar folga, quando podem, para estar com eles.

Para mim o trabalho interfere em quase tudo. Tem vezes que eu chego tão cansada que fico estressada com a minha filha, de tanto trabalhar. Porque eu venho do trabalho, nesse sol quente, de bicicleta, pois mal, mal tenho dinheiro para passagem, e isso me estressa muito. Eu não bato nela, mas me estresso. Eu respondo com ignorância, mas depois eu me arrependo. Deus me livre! (R7).

Eu quase não tenho lazer com os meus filhos, só por causa do meu horário, só às vezes que eu falto e tiro uma folga para ficar com eles (R5).

A flexibilidade proposta e implantada no mundo do trabalho não veio acompanhada de uma flexibilidade nos programas de proteção social. Os governos nacionais buscam ajustar suas economias aos desafios criados pelo mercado global, restringindo e cortando empregos, salários e serviços estatais gratuitos básicos. Nesse processo, a comunidade e as famílias passam a assumir responsabilidades por serviços que o Estado deixa de oferecer. As garantias de níveis mínimos de emprego e salário dos trabalhadores, a saúde e a educação gratuitas como direitos universais estão ameaçadas pelos novos modelos econômicos e políticos (Goldani, 2002). Dessa forma, diante dessa ausência estatal, as redes sociais se tornam cada vez mais importantes.

Castel (1998) analisa as metamorfoses pelas quais vem passando a "questão social" desde o século XIX e aponta que, em face da desfiliação que acompanha a diminuição do Estado de bem-estar social, especialmente na Europa, cresce a importância das redes sociais, visando dar suporte e atenuar as desvantagens sociais a que estão submetidos os trabalhadores, principalmente os que se dedicam a atividades com menor qualificação, como é o caso dos pedreiros e domésticas ouvidos nesta pesquisa.

Algumas trabalhadoras contam com a ajuda das vizinhas para cuidar dos filhos. Porém, como isso nem sempre é possível, são comuns situações em que, para poder trabalhar, a mulher tem que deixar os filhos pequenos sozinhos em casa. Nesses casos, comumente as crianças mais velhas têm a incumbência de cuidar das menores.

Os meus (quando eu saio para trabalhar) têm que ficar sozinhos. A minha tem doze (anos) e o meu tem oito (anos). Eu peço para a minha vizinha ir lá dar comida, pois meu medo é do gás. Já pensou eu chegar em casa e...? (R2).

Esses depoimentos confirmam a importância de grupos que ultrapassam os limites do domicílio (redes sociais de parentes, amigos, vizinhos) como parte fundamental das estratégias para enfrentar as dificuldades e escassez de recursos materiais entre as famílias pobres (Garcia \& Oliveira, 1994, e Gonzáles De La Rocha, 1998, citados por Goldani, 2002). Ressalta-se que as críticas em relação à ausência do Estado na garantia dos direitos sociais mínimos - como saúde e educação - surgiram no grupo das mulheres, pois cabe a elas sincronizar a vida laboral com a vida doméstica.

O tempo dedicado ao trabalho subtrai as atividades de lazer tanto entre homens, como entre as mulheres ouvidas. Porém, alguns deles afirmaram que, mesmo sendo difícil, procuram uma maneira de se divertir, não abrindo mão do lazer em nome do trabalho. Para os homens, esse divertimento está associado a frequentar bares na região.

Até que a gente acha um tempinho, vai no barzinho tomar unzinho... pra relaxar um pouquinho (A8).

[...] Como eu trabalho de sete às cinco, eu saio do serviço e vou para o buteco (V1). 
Entre as trabalhadoras, apenas uma afirmou que não abre mão do lazer - bebendo e dançando -, mesmo que para isso tenha que ficar uma noite sem dormir e trabalhar cedo no dia seguinte. Sua fala se diferenciou das demais, pelo grau de liberdade demonstrado.

Eu trabalhei em Goiabeiras um ano. Uma firma de Curitiba, com 80 peão. De domingo a domingo. Chegava em casa sábado à noite $11 \mathrm{~h}$ da noite. Ia para o Singo's dançar. Chegava, entrava no chuveiro, meio bêbada, botava uma roupa e ia pra firma... fazia o almoço para os 80 peão, eu pegava as roupas deles todinhas e levava para casa. Lavava no domingo e segunda-feira eu entregava tudo passada. Fiz isso um ano. Como eu não posso sair sozinha, meus filhos, uma de 17 o outro de 18, falam assim; "A senhora está muito nova, vamos com nós, você tem que se divertir". "Eu falo para o meu marido assim: 'Fica aí e toma conta do pequeno'" (V6).

\section{A necessidade de boas condições de trabalho para a saúde}

Alguns dos trabalhadores estudados apresentam uma visão ampliada de saúde tal como o conceito definido pelo SUS, explicitado na Constituição e fruto das discussões da VIII Conferência Nacional de Saúde; ou seja, oferecem um discurso no qual as condições de existência, a possibilidade de manter a subsistência e a tranquilidade de oferecer segurança à sua família são fundamentais e encontram-se na base da saúde desejada. Também referem uma ideia holística ao trazer o corpo e o espírito associados à ideia do processo saúde-doença, articulada com as condições materiais de existência. Para eles a doença refere-se a desequilíbrios que afetam de uma só vez o espírito, a alma, o corpo e a matéria. Eles trazem a concepção de saúde-doença como fruto da produção-reprodução social, através do modo e das condições de vida de cada indivíduo na conformação de suas relações da vida em sociedade, ao afirmarem que ter saúde é ter boas condições de vida e a tranquilidade que dela decorre; isso quer dizer: ter boa alimentação, educação, lazer, segurança e ter recursos financeiros para pagar as contas. Essa concepção se assemelha àquela proposta por Dejours (1986) de que a saúde é a liberdade de adaptação. Para o autor pode ser que seja normal ter algumas doenças, desde que se possa tratá-las.

Para outros do grupo, a saúde está associada à possibilidade de executar suas tarefas cotidianas, sobretudo ter força para trabalhar e, dessa forma, cumprir o seu papel de provedor, aquilo que a sociedade e eles próprios esperam. Para eles, uma das condições para sobreviver é trabalhar. E, para trabalhar, é preciso ter saúde, o que, em última instância, quem dá é Deus. Uma vez que Deus lhes dá a força do corpo, cabe a cada um buscar a disposição dentro de si mesmo para o trabalho. Acordar cedo reforça a ideia do homem trabalhador, que com o nascer do sol se mobiliza para o trabalho.

Eu peço a Deus para me manter firme e forte para trabalhar, pois, se eu não tiver força, não tenho ninguém para me sustentar. É eu acordar cedo e ter oportunidade de manter a minha família (A7).

Segundo Minayo (2007), do ponto de vista da classe trabalhadora, duas noções principais estão subjacentes ao tema da doença: a fé em Deus na cura e a relação do adoecimento com a incapacidade de trabalhar. Além disso, para esses trabalhadores, saúde é garantir que a família tenha boas condições de vida. Como é o trabalho que propicia tais condições, pode-se concluir que ter saúde para eles significa poder trabalhar. A representação que se constrói a partir daí tem expressões como "a saúde é tudo" e "a partir do momento que a pessoa adoece não tem como fazer alguma coisa". 
As pessoas ligadas à fé cristã colocam em Deus a causa primeira do aparecimento e da cura das doenças, embora acrescentem causas socioeconômicas, emocionais e naturais ao aparecimento das enfermidades. A característica fundamental da visão religiosa da saúdedoença (ou melhor, da vida) é a relação intrínseca entre fé e a graça. Essa visão está referenciada nas dificuldades do cotidiano e visa à prática, ao resultado concreto: ela traz para perto o milagre e o toma como parte do cotidiano, como solução, às vezes única, para as agruras do dia a dia (Minayo, 1988).

Outro elemento ligado à saúde diz respeito à força física. Como os operários da construção civil tiram seus meios materiais de existência da venda de sua força de trabalho associada à atividade física, necessitam usar intensamente seus corpos e tirar o máximo de proveito deles. $\mathrm{O}$ corpo precisa ser útil. $\mathrm{O}$ corpo é associado a uma máquina sempre em funcionamento para não enferrujar, e o trabalho possibilita isto, na medida em que mantém o corpo em movimento. Se o corpo saudável é um corpo ágil, por oposição, um corpo doente é um corpo emperrado, pesado.

Você quando está trabalhando, está exercitando seu corpo. É uma maneira de você manter a saúde também. Você fica parado, você fica doente (V4).

Alguns assinalam que o prejudicial à saúde é a preocupação, a falta de estabilidade no emprego que impede de planejar o futuro, o "corre-corre do dia a dia" que compromete a mente e o corpo. O "nervoso da vida" devido aos problemas cotidianos, é citado como provocador de ansiedade e adoecimento.

Duarte (1986) ressalta que as classes trabalhadoras urbanas por ele estudadas tendem a apresentar nomenclaturas e explicações sobre a saúde e a doença, especialmente aquelas que afetam a mente, com teorias que remontam aos séculos XVIII e XIX e que, se científicas naquele momento, agora se mostram deslocadas e, por vezes, até com um caráter supersticioso. Assim, a "doença dos nervos" e as representações sobre o sangue transparecem como uma teia de explicações sobre o estar saudável ou não. Daí as expressões "sangue bom", "sangue ruim", ou a célebre explicação de que o mal se assolou porque o "sangue subiu pra cabeça". Seguindo a pista etnográfica nesses dois campos semânticos, Duarte (1986) se detém especificamente sobre as "doenças dos nervos" e verifica que em torno dessa ideia se encontra um campo fértil para a compreensão de questões atinentes às condições de vida, trabalho e responsabilidade. Assim, verifica que saúde como categoria central aglutina uma série de associações entre corpo e espírito, em uma homeostase que, quando quebrada, faz surgir o nervoso, seja por questões internas ou externas, seja o "nervoso como mediação físico-moral" (p. 144).

Minayo (2007), citando uma pesquisa do ENDEF (Estudo Nacional de Despesas Familiares) de 1974, demonstra que as classes populares, quando entrevistadas sobre os perfis de morbimortalidades, classificam em primeiro lugar as "doenças dos nervos" ou "doenças do espírito". Essas doenças são explicadas por eles como um conjunto de ansiedades e insatisfações que vivenciam por causa das "dificuldades da vida", representadas, entre outras, por sobretrabalho, restrições causadas por salários baixos, alimentação insuficiente.

Por consequência, conforme um dos entrevistados, para que não adoeçam e tenham saúde, precisam ter uma harmonia entre todos os elementos anteriormente mencionados. Assim, o estado de saúde é um estado dinâmico.

A princípio eu acho que saúde é estar de bem com a vida. Se você ficar nervoso por um problema qualquer, tudo acaba para ele, seja um problema na família, um filho ou uma esposa doente, e você não consegue resolver. Isso tudo prejudica a saúde, sobretudo os nervos. Você não consegue ir trabalhar tranquilo deixando em casa um filho doente. A saúde, além de estarmos bem fisicamente, precisamos estar bem psicologicamente. Principalmente psicologicamente. A matéria da gente depende muito da cabeça. Se a gente não estiver bem psicologicamente estamos sofrendo, mesmo sem estarmos com um problema no físico. Principalmente o trabalhador que já se 
acostumou a sair cedo de casa e só chegar à noite. Se deixar um problema em casa, às vezes faltou um gás, ele não tem dinheiro para comprar esse gás, ele tá nervoso no serviço (A6).

A Organização Mundial da Saúde (OMS) define saúde não apenas como a ausência de doença, mas como perfeito bem-estar físico, mental e social. Dejours (1986), ao criticar essa definição, afirma que saúde é antes de tudo um fim, um objetivo a ser atingido. Não se trata de um estado de bem-estar. Dessa forma trata-se, mais propriamente, de um estado do qual procuramos nos aproximar, pois o estado de bem-estar não é algo estável que uma vez atingido possa ser sempre mantido.

Quando estimulados a falar sobre os fatores do cotidiano que poderiam prejudicar a saúde, apontam para a falta de infraestrutura de saneamento básico, como esgoto e lixo a céu aberto e pragas urbanas (ratos, baratas e mosquitos). Assim, a necessidade de políticas públicas que garantam boas condições de vida ficou evidenciada, principalmente nos depoimentos das trabalhadoras domésticas. Dessa forma, a ausência de creche ou a falta de critério na distribuição das vagas e a insuficiência de lugares para as atividades extraescolares dirigidas aos filhos figurou como fonte de angústia. Para que essas mulheres consigam tranquilidade é fundamental saber que os filhos estão protegidos e cuidados durante sua ausência, e insistem na necessidade de que o Estado ofereça vagas nas creches para as mães que trabalham fora.

Saúde é ter tranquilidade. É ter um postinho bom, um colégio bom para colocar as crianças para você ficar tranquila. Aí você não adoece, não (R2).

\section{Riscos percebidos e morbidades referidas}

Os trabalhadores apontam diversos riscos de adoecer e morbidades relacionadas à sua ocupação no mercado de trabalho. Entre as trabalhadoras domésticas, os principais fatores de risco apontados foram: o relacionamento patrão-empregada, os produtos químicos (principalmente o cloro) e o risco de queda (quando necessitam limpar janelas). As principais morbidades associadas ao trabalho foram: estresse, alergias, dermatites, problemas respiratórios, rouquidão, dor de cabeça, falta de ar e lombalgia. Referem que continuam trabalhando, mesmo quando doentes, especialmente entre as diaristas.

Para eu sobreviver eu tenho que encarar esse problema assim mesmo. Com dor de cabeça, ou com falta de ar, ou com alguma coisa eu tenho que encarar. Eu preciso sobreviver e criar os meus filhos. Aí o dinheiro que eles pagam à gente, não recompensa o remédio que a gente tem que comprar depois (R3).

Eu trabalho doente, porque se eu faltar eu não vou ter dinheiro. Tem vez que você trabalha tonta, tem dor de cabeça no serviço, dor de coluna. Não existe levar atestado para um dia de faxina. Se eu não for, eu não recebo. Tenho que trabalhar doente. Diarista é bom, porque você recebe mais dinheiro, mas se você faltar... (R12).

Além disso, há o medo do desemprego e o desânimo de ter que enfrentar os mesmos problemas em outro serviço. Dessa forma, se sujeitam diante da necessidade de sobrevivência delas e dos filhos.

A gente é assim: saiu, já sabe que tem outra na porta esperando para entrar, porque o desemprego está terrível aí fora [...]. A gente vai sair dali e ter que encarar um outro na semana seguinte, porque tem as contas para pagar (R6). 
Por outro lado, segundo as trabalhadoras mais velhas, aquelas que aceitam se expor são inexperientes ou tolas. Consideram que as experientes como elas não sofrem acidentes, nem adoecem pelo trabalho, pois já conhecem os riscos e entendem que cabe a cada um não se expor a eles. Talvez o fato de já terem criado os filhos dê a essas mulheres mais autonomia na organização do seu trabalho, fazendo com que não se sujeitem às imposições que consideram injustas e inapropriadas: se recusam a pegar pesos, usam luvas para manipular produtos químicos e não se projetam em janelas.

Quando a pessoa já está acostumada como ela ali, eu, ela ali também. A gente já tira de letra. E nada de se pendurar na janela. Eu sou mesmo abusada. Limpeza na janela eu digo, tô fora. Peso, isso é coisa de homem (V2).

A autoconfiança provém da experiência prática acumulada durante o tempo de serviço. Porém, uma participante afirma que ser submissa é mais valorizado do que a competência no trabalho doméstico. Essa atividade apresenta como características marcantes o isolamento social, a unidade entre o local de trabalho e o de moradia, além da baixa regulamentação social ou estatal, que favorece uma superexploração por parte dos empregadores (Melo, 1998; Milkman, 1998, e Kofes, 2001, citados por Iriart et al., 2008).

Entre os trabalhadores da construção civil, os principais riscos apontados foram: ruído, cargas pesadas, posições inadequadas e os produtos químicos. Em relação ao risco químico, os trabalhadores relataram a preocupação com o caráter insidioso e invisível desse risco. Tanto os trabalhadores autônomos como os que trabalham em grandes empresas não sabem exatamente com o que estão lidando e o que poderá acarretar no futuro, como um veneno invisível que pode prejudicar as pessoas aos poucos.

Dentro da área da $\mathrm{XLP}^{3}[. .$.$] ainda existe o problema do gás \mathrm{CO}$, gás benzeno, diversos tipos de gás, me parece que são umas 8 ou 6 qualidades de gás [...] (A4).

[fala de um trabalhador autônomo] Tem uma coisa muito importante também que é a química do material que a gente trabalha. Porque [se] lá na XLP, mesmo com toda segurança, isso acontece. A gente trabalha com tinner, diversos tipos de cola, tintas, cimentos, todos esses materiais têm química brava. Todos esses se você olhar as recomendações está pedindo para não ingerir, passar na pele, procurar um médico. Eu acho que é tipo um veneno que vai acabando pouco a pouco com você e você não percebe, entendeu? Porque são coisas que estão ali e ninguém percebe (A10).

Um participante relatou ser comum aos trabalhadores da construção civil aprender na prática, sem treinamento sobre as funções e os riscos. Isso demonstra que, diante do descuido com a segurança no trabalho, é a experiência de um saber de ofício adquirido durante a prática do trabalho que mais protege a saúde daquele operário. Dessa forma, é a condição de assalariamento e de subordinação a outros níveis hierárquicos que diminui a autonomia perante os riscos, que, por sua vez, se torna também um risco, à medida que têm que se sujeitar a trabalhar em condições prejudiciais à saúde. O tom dado pelos operários de empresas é diferente dos pedreiros autônomos: eles reconhecem os riscos, mas sentem-se obrigados a realizar a tarefa para garantir o emprego.

$\mathrm{Na}$ construção civil é assim, você não tem profissão. O desvio de função é uma coisa que pode. Uma coisa é o que está na CLT, você entra para trabalhar de pedreiro, você tem que fazer serviço de lavrador, carpinteiro, auxiliar, se besta eles botam você para ler projetos, serviço de encarregado. Quer dizer, tudo que você faz, prejudica a sua saúde. Não tem como (V3).

3 XLP é a sigla fictícia de uma siderúrgica de renome internacional, localizada na região metropolitana da Grande Vitória, ES, especializada na produção de aço. 
Ao discorrer sobre aspectos de organização do trabalho, de segurança e saúde na indústria da construção civil, Medeiros e Rodrigues (2001) afirmam que as condições reais dos canteiros de obra já se configuram como riscos. Não existem procedimentos de execução formalizados na maioria das empresas, existindo, no máximo, instruções verbais; muitas vezes, são os próprios trabalhadores que fazem a regulação desses procedimentos, através de ações informais ou não usuais. Esse saber pragmático é incompleto e pouco tranquilizador, pois é colocado em xeque quando da troca de posto de trabalho ou da instalação de um novo equipamento. Por isso, Dejours (1986) assinala que, para melhorar a saúde e a segurança, tudo o que concerne ao trabalho, às condições de trabalho e à organização do trabalho deveria estar sob controle dos próprios trabalhadores. Ele também afirma que a inteligência prática dos trabalhadores está fundamentalmente enraizada no corpo; sendo assim, qualquer evento que rompa a rotina ou ocasione desagrado - um ruído, uma vibração, um cheiro, um sinal visual pode alertar o sujeito, porém, primeiro, o seu corpo e os seus sentidos (Dejours, 1993). Mas, para que isso ocorra e seja efetivo, é necessária uma experiência vivida previamente pelo corpo inteiro da situação comum de trabalho. É essa inteligência, chamada pelo autor de inteligência astuciosa, que proporciona vários dos ajustes necessários à organização do trabalho e à prevenção de acidentes.

Um único episódio de acidente de trabalho foi citado e, segundo eles, estava associado à falta de experiência do trabalhador. Entretanto, reconhecem que há uma tendência de ocultamento do fato pelas empresas.

Tem risco de acidentes. Cortar mármore, um disco cego, por exemplo, se ele agarrar na pedra ali, e o camarada não tem o hábito, ele, na verdade, não sabe utilizar o manguito. Aquilo está arriscado a voltar na mão dele e cortar a mão dele. Um exemplo do que acontece na área da XLP, o rapaz estava cortando com uma circular, eu não tenho certeza, mas todo mundo desconfiou que aquele disco estivesse trincado. Ele meteu o disco na madeira, na hora que ele encostou lá, o disco terminou de trincar, voou uma lasca e atingiu o outro [trabalhador] no pescoço. Eu não sei o que realmente aconteceu, porque nessas áreas industriais é tudo por debaixo dos panos. Você pode reparar que nunca morre ninguém lá dentro, não morre. Nós que estamos lá dentro sabemos, mas não morre ninguém lá dentro (V3).

Os trabalhadores citam que a tentativa de ocultação das mortes e adoecimentos causados pela organização do trabalho é motivada por interesses econômicos.

Não morre ninguém lá dentro. Quem vai querer um produto cheio de sangue? Quem vai comprar isso lá fora? Começa a divulgar isso. Aonde vão os preços da XLP e YVA ${ }^{4}$ ? O preço disso? E aí como é que fica? Não é que eles se importam com as mortes de quem está aqui. O que importa são os valores (V3).

De uma maneira geral, tanto as trabalhadoras domésticas como os trabalhadores da construção civil tenderam a minimizar o risco de se acidentarem. Não admitir que haja acidentes talvez seja um mecanismo de defesa diante do sofrimento psíquico relacionado à dificuldade de interferir nas condições reais de trabalho. Athayde (1996) observou que na construção civil há negação do quadro de violência sobre a saúde e segurança e uma tendência a reforçar a tese de que os acidentes acontecem por falha humana. Para Dejours (2003), a consciência aguda do risco de acidente, mesmo sem maiores envolvimentos emocionais, obrigaria o trabalhador a tomar tantas precauções individuais que ele se tornaria ineficaz do ponto de vista da realização do seu trabalho.

Entre os trabalhadores que participaram da pesquisa, entretanto, há também a percepção de que o acidente é expressão de uma dimensão maior, que é a organização do

4 YVA é a sigla fictícia de uma mineradora multinacional que produz e comercializa minério de ferro, pelotas, níquel, concentrado de cobre, carvão, bauxita, alumina, alumínio, potássio, caulim, manganês e ferroligas. 
trabalho, a rotina do dia a dia, reconhecida como "bruta". Dessa forma, mesmo a utilização dos equipamentos de proteção individual (EPI) não seria capaz de lhes proteger de muitos outros acidentes e doenças adquiridas no trabalho.

Eu não considero que foi um acidente. A rotina que tem lá dentro, ele não aguentou, e existem muitos ali, eu conheço muitos que ali dentro perderam a saúde (A4).

Os EPIs só resolvem para alguns acidentes, mas sobre outros não tem como. Construção civil é peso. Se o cara trabalhar a semana toda colocando piso, que coluna vai aguentar? (V1).

Os trabalhadores com vínculos autônomos também estão sujeitos a riscos. Porém, isso é compensado com a maior possibilidade de controlar sua exposição, diferentemente de um operário que se subordina a uma forma de organização do seu trabalho e um ritmo, que não é o dele. $\mathrm{O}$ autônomo, apesar de às vezes se impor um ritmo maior para auferir maior retorno financeiro com seu trabalho, tem maior controle sobre a organização do seu trabalho.

Quando estimulados a falar sobre os mecanismos de proteção no ambiente de trabalho, não citaram nenhum tipo de proteção coletiva e imediatamente falaram dos equipamentos de proteção individual (EPI). Quanto ao uso do EPI, também há um tom diferenciado entre os operários de grandes empresas e os autônomos. Os autônomos usam os EPI quando entendem que devem e não os usam se consideram que podem prejudicar mais do que ajudar. Nas empresas eles não têm esse direito à negociação e usam porque é obrigatório. Essa norma externa, junto com outras tantas que a organização do trabalho traz, pode colocar o trabalhador ainda em maior risco. Apesar de estar usando um equipamento que deveria protegê-lo, ele, por si só, não consegue fazê-lo, o que se torna perceptível à medida que os operários continuam adoecendo. Mesmo com a consciência dos riscos ambientais (físicos e químicos), muitos trabalhadores, principalmente os informais, não costumam usar nenhum equipamento de proteção individual, e alguns dos motivos citados foram serem incômodos, não terem costume, diminuírem a agilidade necessária para o trabalho e que, muitas vezes, não resolve.

Mas o que acontece é o seguinte, o EPI te ajuda, ele não resolve o problema. Em relação à poeira, você usa o respirador, mas ele não vai evitar que amanhã você tenha um problema de pulmão, um problema respiratório, e outros mais (V3).

Em relação ao uso de EPIs, a gente vai cortar uma parede, por exemplo. Usar uma máscara e óculos não dá certo. Se você usar os dois a respiração embaça os óculos. Ou você respira poeira, ou tira os óculos (V5).

A atitude de não usar o EPI pode ser também demonstração de bravura e virilidade, imagem assumida principalmente na presença de outros companheiros de trabalho.

O cara que trabalha na construção como autônomo criou um hábito de não se proteger, e quando está trabalhando com outro, e coloca uma máscara: Esse aí é bichinha, é frescura dele. Não sabem a necessidade que tem! (A12).

Em alguns depoimentos, demonstram perceber que os riscos aos quais estão expostos são maiores do que a proteção que podem obter com o EPI; então, atribuem a Deus essa proteção em situações nas quais não há controle e quando não têm com quem contar. Dessa forma, somente Deus é quem pode determinar a ocorrência dos acidentes e, consequentemente, protegê-los, também. A fé funciona, então, como uma defesa contra os perigos do trabalho.

Dentro da área da XLP eles trabalham muito em cima da segurança no trabalho. Mas mesmo com tudo isso a dificuldade ali é grande, porque ali ainda existe o problema do gás CO, gás benzeno, diversos tipos de gás, me parece que são umas oito ou seis qualidades de gás. Ainda o 
que prejudica a gente ali dentro é o ruído como ele falou, eles têm toda a proteção, é uso obrigatório, máscara, óculos, fone de ouvido, mas com tudo isso a dificuldade é grande devido à poluição, tanto que o cara que trabalha lá dentro muitas vezes sente dor nos ossos, muitas pessoas... Eu agradeço a Deus por ainda não estar com esses problemas, mas tem pessoas ali dentro com problemas nos ossos, dor de cabeça forte. Eu levei um irmão pra lá, ele trabalhou comigo um ano, se eu não tiro ele dali de dentro ele tinha morrido instantaneamente. Ele passou a sentir problemas que nunca tinham acontecido na vida dele. Problemas na mente, ele ficou esquecido, tremia, perdia o lugar onde tava, eu não sei explicar direitinho o que é. O que sei é que hoje graças a Deus ele encostou e está aí sobrevivendo (A4).

Por fim, em relação às morbidades, os trabalhadores da construção civil relataram principalmente: perda auditiva, diminuição da acuidade visual, dores nas costas, dores nos ossos, dores de cabeça, transtornos mentais, dores nos membros (superiores e inferiores), dermatites e alergias.

\section{Considerações finais}

Este estudo contribuiu para aumentar o conhecimento sobre as relações entre trabalho e processo saúde-doença sob a ótica de trabalhadoras domésticas e trabalhadores da construção civil. Identificadas como as duas categorias profissionais mais numerosas na região estudada e sendo, provavelmente, a realidade da maioria dos grandes centros urbanos do País, espera-se que esses resultados favoreçam a inserção de ações de Saúde do Trabalhador na atenção básica.

O estudo mostrou que, devido ao menor nível socioeconômico e de escolaridade, esses trabalhadores não têm muitas escolhas, diante da necessidade de inserir-se precocemente no mercado de trabalho. Apesar de serem ocupações pouco valorizadas socialmente, que apresentam fraca regulamentação institucional e precarização das condições e relações de trabalho, não deixam de despertar o sentimento de dignidade, sobretudo nos homens, pois algumas mulheres relataram sentir vergonha de sua ocupação. Ainda que sejam atividades extremamente penosas, são valorizadas por garantir a sobrevivência individual e da família. Além disso, a extensa jornada permite poucas oportunidades de lazer e de encontros com a família. Dessa forma, se veem impedidos de ascender socioeconomicamente, na medida em que não conseguem dedicar-se aos estudos, o que poderia talvez possibilitar melhores empregos.

Percebemos também algumas especificidades de gênero: o trabalhador da construção civil mantém o seu papel de provedor, enquanto as trabalhadoras se dividem entre o trabalho fora de casa (complementar ou, às vezes, essencial) e as "obrigações" do lar. Algumas relataram a autonomia gerada pelo salário como algo prazeroso, mesmo sendo mal remuneradas. Essas diferenças também se destacaram em outros aspectos da relação do trabalho com a vida, como, por exemplo, a falta de tempo no cuidado dos filhos, que parece gerar mais angústia nas mulheres do que nos homens.

Tanto os trabalhadores quanto as trabalhadoras reconhecem que o processo saúdedoença está relacionado, em parte, às causas sobrenaturais (desígnios divinos) e à existência de boas condições de vida, levando a uma compreensão de que sua produção depende de uma ação intersetorial.

Identificam muitos riscos ocupacionais aos quais estão expostos e percebem que as empresas tendem a ocultá-los, mantendo-os na ignorância para que não possam contrapor-se, prejudicando, dessa forma, a imagem perante a sociedade. Quando conhecedores dos riscos, principalmente aqueles que são autônomos, podem controlar melhor a organização da sua atividade e, consequentemente, desses riscos. 
Assim, a condição de serem trabalhadores os coloca na posição de protagonistas numa realidade de vida penosa na qual, através do trabalho, assumem suas responsabilidades na transformação de suas vidas. Apesar da crença em Deus, em nenhum momento se colocam em situação passiva na luta pela vida, principalmente na subsistência, como também na busca do prazer.

Alguns aspectos dessa realidade - que lhes causa constrangimentos, sofrimentos e adoecimento - devem ser observados na formulação de políticas apropriadas, por parte de legisladores e gestores públicos. Nesse sentido, cabe destacar a necessidade da apresentação de medidas que favoreçam superar o destino que lhes impede de conseguir melhorias nas relações de contratação do trabalho, devido à baixa escolaridade, através de políticas de regulação do horário de trabalho compatível com a penosidade do trabalho e de capacitação dos trabalhadores. Da mesma forma, o incremento de políticas que assumem a responsabilidade pública pela reprodução social - por exemplo, escolas em tempo integral, seguras e de qualidade, para crianças e adolescentes - poderia liberar as mães trabalhadoras desse encargo que as relações sociais de gênero insistem em manter.

Por fim, a clareza da ligação entre o trabalho e o processo saúde-doença coloca em cheque o modelo assistencial e a concepção de saúde biomédica ainda predominante no SUS. A inserção da Saúde do Trabalhador na atenção básica, o reconhecimento da condição de usuários-trabalhadores por parte dos trabalhadores da saúde é condição necessária para a modificação do modelo e dos processos de trabalho em saúde, considerando a participação legítima desses usuários na vigilância dos ambientes de trabalho e dos riscos relacionados às relações e condições de trabalho.

\section{Referências}

Alves, G. (2000). O novo (e precário) mundo do trabalho: reestruturação produtiva e crise do sindicalismo. São Paulo: Boitempo.

Athayde, M. R. C. (1996). Psicodinâmica do trabalho. In M. R. C. Athayde. Gestão de coletivos de trabalho e modernidade, questões para a engenharia de Produção. Tese de Doutorado, Programa de Pós Graduação em Engenharia de Produção, Universidade Federal do Rio de Janeiro, Rio de Janeiro.

Borges, Â. (2006). Impacto do desemprego e da precarização sobre as famílias metropolitanas. Revista Brasileira de Estudos Populacionais, 23 (2), 205-222.

Fórum Itinerante e Paralelo sobre a Previdência Social. (2007). Carta aberta das mulheres. Brasília.

Coutinho, M. C. \& Gomes, J. S. (2006). Sentidos do trabalho: reflexões a partir de uma oficina vivencial desenvolvida com jovens. Pesquisas e Práticas Psicossociais, 1 (1), 1-11.

Cyrino, R. (2009). Trabalho, temporalidade e representações sociais de gênero: uma análise da articulação entre trabalho doméstico e assalariado. Sociologias, 21, 66-92.

Dejours, C. (1986). Por um novo conceito de saúde. Revista brasileira de Saúde ocupacional, 14 (54), 7-11.

Dejours, C. (1993). Inteligência operária e organização do trabalho: a propósito do modelo japonês de produção. In H. Hirata (Org.), Sobre o "modelo" japonês (pp. 281-309). São Paulo: Edusp.

Dejours, C. (2003). A loucura do trabalho: estudo de psicopatologia do trabalho (5 $5^{\underline{a}}$ ed.). São Paulo: Cortez.

Dias, E. C. (2007). A inserção das ações de saúde do trabalhador no Sistema Único de Saúde: a estratégia da Rede Nacional de Atenção Integral à Saúde do Trabalhador [CD-ROM]. In Textos de apoio às oficinas temáticas. Rio de Janeiro: Fiocruz.

Dias, E. C. \& Hoefel, M. G. (2005). O desafio de implementar as ações em saúde do trabalhador no SUS: a estratégia da RENAST. Ciência e Saúde Coletiva, 10 (4), 817-827.

Duarte, L. F. D. (1986). Da vida nervosa nas classes trabalhadoras urbanas. Rio de Janeiro: Zahar. 
Goldani, A. M. (2002). Família, gênero e políticas: famílias brasileiras nos anos 90 e seus desafios como fator de proteção. Revista Brasileira de Estudos Populacionais, 19 (1) 29-48.

Hassen, M. N. (2002). Os grupos focais de intervenção no projeto sexualidade e reprodução. Horizontes Antropológicos, 8 (17), 159-177.

Hirata, H. (2002). Globalização e divisão sexual do trabalho. Cadernos Pagu, 17-18, 139-156.

Hirata, H. (2009). A precarização e a divisão internacional e sexual do trabalho. Sociologias, 21, 24-41.

Hirata, H. \& Kergoat, D. (2007). Novas configurações da divisão sexual do trabalho. Cadernos de Pesquisa, 37 (132), 595-609.

Instituto Brasileiro de Geografia e Estatística (2000). Censo demográfico 2000. Brasília: IBGE.

Iriart, J. A. B., Oliveira, R. P., Xavier, S. S., Costa, A. M. S., Araújo, G. R. \& Santana, V. S. (2008). Representações do trabalho informal e dos riscos à saúde entre trabalhadoras domésticas e trabalhadores da construção civil. Ciência e saúde coletiva, 13 (1), 165-174.

Kergoat, D. (2010). Dinâmica e consubstancialidade das relações sociais. Novos Estudos CEBRAP, 86, 93-103.

Medeiros, J. A. D. M. \& Rodrigues, C. L. P. (2001). A existência de riscos na indústria da construção civil e sua relação com o saber operário [CD ROM]. In Anais do XXI Encontro Nacional de Engenharia de Produção. Salvador.

Minayo, M. C. S. (1988). Saúde-doença: uma concepção popular da etiologia. Caderno de Saúde Pública, 4 (4), $356-$ 362.

Minayo, M. C. S. (2007). O desafio do conhecimento: pesquisa qualitativa em saúde (10ª ed.). São Paulo: Hucitec.

Poldi, R. M. V. (2007). Perfil sociodemográfico e de inserção no trabalho de usuários das Unidades de Saúde da Família da Serra, ES. Monografia do Curso de Especialização em Odontologia do Trabalho, Associação Brasileira de Odontologia, Vitória.

Poldi, R. M. V. (2008). Relação entre trabalho e necessidades de saúde sob a ótica de moradores adscritos a uma unidade de Saúde da Família no município da Serra, ES. Dissertação de Mestrado, Programa de Pós-Graduação em Saúde Coletiva, Universidade Federal do Espírito Santo, Vitória.

Rodrigues, A. M. (1978). Operário, operária: estudo exploratório sobre o operariado industrial da Grande São Paulo. São Paulo: Símbolo.

Santos, L. (2001). Saúde do trabalhador: conflito de competência, União, Estados e Municípios. Brasília: MS/OPAS.

Souza, L. N. (2001). Uma análise da inserção feminina no mercado de trabalho da RMS: uma leitura a partir dos dados da PED. Dissertação de Mestrado, Programa de Pós Graduação em Economia, Faculdade de Ciências Econômicas, Universidade Federal da Bahia, Salvador.

Valla, V. V. (2000) Redes sociais, poder e saúde à luz das classes populares numa conjuntura de crise. Interface Comunicação, Saúde, Educação, 4 (7), 37-56.

\section{Endereço para correspondência}

robvello@hotmail.com, luiz.henrique.borges@terra.com.br, dalbello@intervip.com.br 